Journal of Accident and Emergency Medicine 1994 $11,25-31$

\title{
Head injuries in the accident and emergency department: are we using resources effectively?
}

\author{
S.A. WALLACE, ${ }^{1}$ J.BENNETT, ${ }^{1}$ C.A.PEREZ-AVILA ${ }^{2}$ \& R.W. GULLAN ${ }^{3}$ \\ ${ }^{1}$ Department of Public Health Medicine, Brighton General Hospital, Elm Grove, Brighton, \\ ${ }^{2}$ Accident and Emergency Department, The Royal Sussex County Hospital, Eastern Road, Brighton \\ ${ }^{3}$ Department of Neurosurgery, The Brook General Hospital, Shooters Hill Road, London.
}

\section{SUMMARY}

This paper reports a retrospective criterion based audit which reviewed head injury management in two accident and emergency (A\&E) departments. Management was compared with regionally agreed criteria ${ }^{1}$ for ordering a skull radiograph (SXR) and a computerized tomogram (CT scan) and for admission, and the quality of medical documentation was assessed. A total of 158 patients were reviewed and 132 patients $(84 \%)$ satisfied the three key areas of recommended head injury management. Failures to satisfy recommended guidelines were present in 19 patients $(12 \%)$ for SXR, four $(2 \%)$ for admission and three (2\%) for CT scanning. Three skull fractures (two in young babies) would have been missed if the criteria had been adhered to strictly. There was one adverse outcome when a patient who should have been admitted returned to A\&E 8 days after initial attendance with a subdural haemorrhage and died shortly afterwards. Apart from 'loss of consciousness', the quality both in content and legibility of the medical documentation was poor. The result of $84 \%$ correctly managed patients may be over-optimistic according to the criteria used. Although criteria have a valuable role to play, there are problems with prescriptive standard setting. A recommendation was made to develop a head injury pro forma to address the poor quality medical documentation and it was also recommended that the SXR, CT scan and admission criteria for babies and young children be reviewed.

Keywords: audit, documentation, guidelines, head injury, pro forma.

\section{INTRODUCTION}

Correspondence: Dr Simon A. Wallace 46 Eaton Place, Brighton, East Sussex BN2 1EG
Head injuries are an important cause of morbidity, mortality and long-term disability, often in otherwise healthy young people. Their management in the A\&E department plays a key role in the diagnosis and treatment of potentially avoidable secondary brain damage.

It is more than 15 years since Jennett first drew attention to the need for improved organization of the system for managing patients with a head injury. ${ }^{2}$ In 1986, a Commission by the Royal College of Surgeons of England ${ }^{3}$ made recommendations for the organization of services provided for head injury cases in England and Wales. Those recommendations have since been endorsed and several regional working parties have been established. Regional guidelines for head injury management have been developed, ${ }^{1,4}$ and individual districts have been encouraged to develop suitable modifications tailored to their own resources and requirements.

In recent years, several papers ${ }^{5-8}$ have drawn attention to the economy of bed usage and radiological services which could be obtained from better triage: to the improved results which can be obtained from early admission to specialized neurosurgical units; to the enormous diagnostic and prognostic value of computed tomography; to the benefit of intensive care facilities; and to the contribution of skilled rehabilitation.

The use of skull radiography in the management of these patients is common but controversial. ${ }^{9-16}$ One study has suggested that the number of skull radiographs carried out on new patients attending A\&E departments in the United Kingdom could be reduced from approximately 600000 to 168000 per annum using guidelines, ${ }^{17}$ a trend recently confirmed by the Royal College of Radiologists Working Party. ${ }^{18}$ At 1992 prices, ${ }^{19}$ the potential saving could be around £8.9 million per annum.

The application of a set of criteria in an A\&E department in Nottingham ${ }^{20}$ led to a significant drop in the number of patients admitted with a head injury. Admissions fell from 941 before the policy was implemented to 536 and 460 admissions in the subsequent 2 years, without adversely affecting the 
S.A. Wallace et al. outcome of head-injured patients; this has been confirmed by other studies. ${ }^{17,21,22}$

CT scanning has shown that cerebral compression may be present before it is clinically detectable. ${ }^{3}$ Appropriate use can facilitate early surgical intervention, often with improved outcomes as a result of reductions in mortality and morbidity. ${ }^{8,23-28}$. Although guidelines for the use and availability of CT scanning are becoming established, there are limited resources to effect them. ${ }^{1,3,28}$

The Department of Health and Social Services (DHSS) seminar on the management of head injuries in Harrogate in 1983 produced guidelines for SXR and hospital admission. ${ }^{29}$ However, appropriate action has not necessarily been widely adopted.

The acute management of head injuries has been an area of concern and discussion among public health physicians and hospital clinicians in Brighton. The Department of Public Health Medicine convened a Head Injury Group to address the 'appropriate' usage of SXR, CT scanning and admission to hospital according to guidelines based on national recommendations, ${ }^{3}$ as supported in the South East Thames Region's own specific guidelines. ${ }^{1}$ To do this, a retrospective criterion based audit was performed in two A\&E departments in Brighton.

\section{METHODS}

The Brighton Head Injury Group comprised doctors from public health medicine, A\&E, general and paediatric surgery, radiology and anaesthetics.

The technique of criterion based audit described by Shaw ${ }^{30,31}$ was used for the study and the criteria chosen are listed in Table 1. Although the standard used for each criterion was ' $100 \%$ completion in each set of medical records', they could not always be applied rigidly in every case. Firstly, the criteria for CT scan were not applicable in those patients who had only suffered a minor head injury. Secondly, a few allowable exceptions to the criteria were permitted, where one criteria took priority over the next. For example, if a seriously head-injured patient required an urgent CT scan, then the SXR was omitted because the clinical information from the latter could be obtained from the scan. Thirdly, symptoms not applicable to babies and young children were not included for this age group e.g. 'post-traumatic amnesia' (and hence its length of duration), 'headache', 'disturbed vision' and 'having taken alcohol or drugs recently'.
Table 1. The criteria used in the study for ordering an SXR and a CT scan and for admission

Skull Radiograph (SXR)

(1) Any loss of consciousness.

(2) Post-traumatic amnesia exceeding $10 \mathrm{~min}$.

(3) Suspected penetrating injury.

(4) Intoxication, alcohol or drug.

(5) Difficulty in assessing the patient, e.g. the young, the elderly, those with epilepsy.

(6) Neurological signs, disorientation or confusion.

(7) Leaking of cerebrospinal fluid and/or blood from the nose/ear.

(8) Haemotympanum.

(9) Significant scalp laceration (exceeding $10 \mathrm{~cm}$ ).

(10) Significant scalp haematoma (exceeding $10 \mathrm{~cm}$ ).

CT scan

(1) Glasgow Coma Score of 8 or less.

(2) Fall of 2 points in Glasgow Coma Score within $1 \mathrm{~h}$.

(3) Fits.

(4) Unequal or unreactive pupils.

(5) Skull fracture extending for more than $10 \mathrm{~cm}$.

(6) Extensive soft tissue injury to scalp.

(7) Focal neurologial signs.

(8) Children - not withdrawing to pain.

\section{Admission}

(1) Unconscious for more than $10 \mathrm{~min}$

(2) Post traumatic amnesia for more than $10 \mathrm{~min}$.

(3) Skull fracture.

(4) Abnormal neurological examination.

(5) Falling level of consciousness/more tired than usual.

(6) Severe headache.

(7) Persistent vomiting

(8) Disturbance of vision

(9) Strange behaviour.

(10) Inadequate supervision at home.

injured patients were obtained for a chosen 3-month period from several sources: the District Information System (DIS); the Unisys A\&E computer at the main hospital; the CT scan register; the manual A\&E administration system; and the surgical ward admission register at the childrens hospital.

As the number of patients with a head injury who had either died, had a CT scan or had a skull fracture was important, it was decided to study all these cases. Although the resultant sample would be skewed, this effect would be minimal as the numbers involved were relatively small. For the remaining head injury cases from the 3-month study period, a random sample of patients was used. This sample represented $18 \%$ of the total number of head injuries seen in the 3-month period.

A data extraction form was developed to check 
Head injuries in A\&E whether the relevant information from the medical records adhered to the pre-determined criteria. In those cases where there was difficulty deciding whether the management had been correct, two consultants from the Head Injury Group peer reviewed the case.

\section{RESULTS}

A total of 950 patients with a head injury were seen in both A\&E departments during the 3-month study period (April-June 1989). Of the 171 patients in the original sample, only 158 could be analysed. Of the $13(8 \%)$ patients who were not included, six $(4 \%)$ were omitted because of missing medical records and $7(4 \%)$ were omitted as a result of miscoding of the original diagnosis as a head injury.

Of the 158 patients: $81(51 \%)$ were children under the age of 16 years; $78(49 \%)$ had a SXR; $84(53 \%)$ were sent home; 74 (47\%) were admitted; 17 (11\%) had a CT scan; $20(13 \%)$ had a skull fracture; and six $(4 \%)$ died. A total of $132(84 \%)$ patients were judged to have received appropriate management and $26(16 \%)$ inappropriate management according to the criteria.

Table 2 gives a complete breakdown of each of the categories analysed and the numbers who received inappropriate management according to the criteria used in the study.

\section{Criteria for ordering a skull radiograph}

Table 2 gives an analysis of the appropriate and inappropriate use of SXRs and divides the 19 (24\%) patients who were investigated inappropriately into adults and children, and differentiates whether they were admitted or sent home. Of the $78(49 \%)$ patients who had an SXR, 29 were children (36\% of all children seen) and 49 were adults ( $64 \%$ of all adults seen).

Two of the patients who were managed inappropriately were children who, on the basis of the criteria, were not considered to require an SXR, but had one performed and in both cases a skull fracture was diagnosed with no adverse outcome.

Of the remaining patients in this group who were

Table 2. Summary of analysis of a sample of patients with a head injury admitted to hospital or sent home (April-June 1989)

\begin{tabular}{|c|c|c|c|c|c|c|c|c|}
\hline & $\begin{array}{l}\text { Appropriate } \\
\text { management }\end{array}$ & $\begin{array}{c}\text { Inappropriate } \\
\text { SXR }\end{array}$ & $\begin{array}{c}\text { Needed an } \\
\text { SXR }\end{array}$ & $\begin{array}{l}\text { Inappropriate } \\
\text { admission }\end{array}$ & $\begin{array}{c}\text { Needed } \\
\text { admission }\end{array}$ & $\begin{array}{c}\text { Inappropriate } \\
\text { CT scan }\end{array}$ & $\begin{array}{l}\text { Needed a } \\
\text { CT scan }\end{array}$ & Total \\
\hline \multicolumn{9}{|l|}{ Children admitted with no } \\
\hline skull fracture & $21(13 \%)$ & $2(1 \%)$ & $1(1 \%)$ & 0 & 0 & 0 & 0 & $24(15 \%)$ \\
\hline \multicolumn{9}{|l|}{ Children admitted with a } \\
\hline skull fracture & 0 & $2(1 \%)$ & 0 & 0 & 0 & 0 & 0 & $2(1 \%)$ \\
\hline \multicolumn{9}{|l|}{ Adults admitted with no } \\
\hline skull fracture & $29(19 \%)$ & 0 & 0 & 0 & 0 & 0 & 0 & $29(19 \%)$ \\
\hline \multicolumn{9}{|l|}{ Adults admitted with a } \\
\hline skull fracture & $10(6 \%)$ & $1(1 \%)$ & 0 & 0 & 0 & $2(1 \%)$ & 0 & ${ }^{*} 13(8 \%)$ \\
\hline \multicolumn{9}{|l|}{$\begin{array}{l}\text { Adults admitted with or } \\
\text { without a skull fracture }\end{array}$} \\
\hline who died & $5(3 \%)$ & 0 & 0 & 0 & 0 & 0 & $1(1 \%)$ & $6(4 \%)$ \\
\hline \multicolumn{9}{|l|}{ Total number of patients } \\
\hline admitted & $65(41 \%)$ & $5(3 \%)$ & $1(1 \%)$ & 0 & 0 & $2(1 \%)$ & $1(1 \%)$ & $74(47 \%)$ \\
\hline \multicolumn{9}{|l|}{ Children set home from } \\
\hline A\&E & $47(30 \%)$ & $5(3 \%)$ & $+1(1 \%)$ & 0 & $2(1 \%)$ & 0 & 0 & $55(35 \%)$ \\
\hline \multicolumn{9}{|l|}{ Adults sent home from } \\
\hline$A \& E$ & $20(13 \%)$ & $3(2 \%)$ & $4(2 \%)$ & 0 & $2(1 \%)$ & 0 & 0 & $29(18 \%)$ \\
\hline \multicolumn{9}{|l|}{ Total number of patients } \\
\hline seen and sent home & $67(43 \%)$ & $8(5 \%)$ & $5(3 \%)$ & 0 & $4(2 \%)$ & 0 & 0 & $84(53 \%)$ \\
\hline $\begin{array}{l}\text { Total number of patients } \\
\text { admitted and sent home }\end{array}$ & $132(84 \%)$ & $13(8 \%)$ & $6(4 \%)$ & 0 & $4(2 \%)$ & $2(1 \%)$ & $1(1 \%)$ & $158(100 \%)$ \\
\hline
\end{tabular}

Notes: The percentages have been rounded up.

* Four of the six deaths had a skull fracture. Therefore, the total numbers of adult skull fractures in this sample was $17(13+4)$.

${ }^{+}$This patient was sent home with a skull fracture which was diagnosed the following day. 
S.A. Wallace et al. managed inappropriately, there was no evidence from the medical records that their outcome was affected by the management that they received.

Table 3 demonstrates the degree of completion in the medical records of the criteria for skull radiography. This refers to doctors' recording negative as well as positive findings.

Of the 78 SXRs ordered by a doctor, only 27 $(35 \%)$ cases had a reason for the request documented in the medical notes. However, of these 78 radiographs ordered, an opinion about the presence or absence of a skull fracture by the requesting doctor was found in 67 (86\%) records.

\section{Criteria for admission}

Table 2 gives an analysis of the 74 (47\%) patients who were admitted to hospital. All cases were considered to be appropriate.

However, four patients (two children and two adults representing $2 \%$ of all patients seen) were identified who should have been admitted, but were sent home from the A\&E department. One of these four patients returned 8 days following initial presentation having collapsed with a subdural haemorrhage and died shortly afterwards. There were no adverse outcomes in the other three.

As with the criteria for SXRs, the written details addressing the criteria for admission and discharge were poor both in content and quality, with only $50 \%$ of case notes considered to have adequate clinical detail. Only 89 (56\% of all patients seen) case notes gave a written explanation as to why the patient had been admitted or sent home. This was better addressed for children $(67 \%$ of all children seen) than for adults ( $46 \%$ of all adults seen).

\section{Criteria for ordering a CT scan}

Of $17(11 \%$ of all patients seen) patients who were scanned, $16(21 \%)$ were adults and one $(1 \%)$ was a child. Table 2 shows that two (12\%) of the CT scans were considered unnecessary according to the criteria and one patient should have had a scan, but for clinical reasons was not scanned until $24 \mathrm{~h}$ later. Although one of these patients died, none were judged by peer review to have had a worse outcome as a result of their management.

Although the content of clinical information in the notes of the more seriously injured group was more detailed, only nine sets of records $(53 \%)$ had a reason for ordering a CT scan recorded by the doctor. There were no written details in the A\&E medical records to suggest that there were any problems ordering or obtaining a CT scan. Of the 17 CT scans performed, 12 (71\%) showed intracranial pathology.

\section{DISCUSSION}

The main aim of this study was to determine whether the management of head injuries in Brighton corresponded to recommended guidelines suggested by the South East Thames Regional Head Injury Group. ${ }^{1}$ The major objective of ordering SXRs and CT scans or admitting the patient to hospital is to help prevent secondary brain damage, especially the effects of delayed intracranial haematoma, such as an extradural haematoma. The occurrence of such a complication is rare in relation to the total population of head-injured patients, ${ }^{32}$ and could be

Table 3. Evidence in the medical notes that the criteria for ordering a skull radiograph had been documented

\begin{tabular}{|c|c|c|c|}
\hline $\begin{array}{l}\text { Criteria for ordering } \\
\text { an SXR }\end{array}$ & Children & Adults & Mean \\
\hline $\begin{array}{l}\text { Loss of consciousness } \\
\text { Length of time }\end{array}$ & $76(94)$ & $67(87)$ & $143(91)$ \\
\hline $\begin{array}{l}\text { uncounscious } \\
\text { Post-traumatic }\end{array}$ & $5(100)$ & $33(97)$ & $38(97)$ \\
\hline amnesia (PTA) & $\mathrm{NA}^{+}$ & $26(34)$ & $26(34)$ \\
\hline $\begin{array}{l}\text { Length of post- } \\
\text { traumatic amnesia }\end{array}$ & $\mathrm{NA}^{+}$ & $9(60)$ & $9(60)$ \\
\hline $\begin{array}{l}\text { Suspected penetrating } \\
\text { injury }\end{array}$ & $4(5)$ & $3(4)$ & $7(4)$ \\
\hline Alcohol/drug recently & $\mathrm{NA}^{+}$ & $33(43)$ & $33(43)$ \\
\hline Neurological signs & $51(63)$ & $62(81)$ & $113(72)$ \\
\hline $\begin{array}{l}\text { Blood/CSF* from } \\
\text { ear/nose }\end{array}$ & $10(12)$ & $16(21)$ & $26(16)$ \\
\hline Haemotympanum & $7(9)$ & $0(0)$ & $7(4)$ \\
\hline $\begin{array}{l}\text { Scalp laceration } \\
\text { Length of scalp }\end{array}$ & $42(52)$ & $47(61)$ & $89(56)$ \\
\hline laceration & $22(81)$ & $25(61)$ & $47(70)$ \\
\hline $\begin{array}{l}\text { Scalp haematoma } \\
\text { Length of scalp }\end{array}$ & $44(54)$ & $34(44)$ & $78(49)$ \\
\hline haematoma & $2(7)$ & $4(15)$ & $6(11)$ \\
\hline
\end{tabular}

Notes: The numbers and percentages (brackets) refer to the criteria being documented as either a positive or negative finding in the medical notes. For example, out of the sample of $158,143(91 \%)$ sets of notes documented whether the patients had been unconscious or not. There was no need to document length of time unconscious if the patient had not been unconscious. Hence, out of 39 patients who had been unconscious, $38(97 \%)$ had the length of time appropriately documented.

* CSF, cerebrospinal fluid, ${ }^{+} \mathrm{NA}$, not assessed in babies and children. 
Head injuries in A\&E likened to 'looking for a needle in a haystack'. One study suggets that the incidence of unsuspected intracranial haematoma with skull fracture among patients with uncomplicated head injury who had been radiographed was 1 in $4800 .^{33}$

The overall results of this study suggest that $84 \%$ of the sample were managed appropriately according to the criteria under consideration. If the remaining 27 patients $(16 \%)$ were managed inappropriately (representing $18 \%$ of the total number of head injuries seen in the 3-month period), then the possibility of several hundred such patients annually stresses the importance of this diagnosis. With the death of one of these patients being potentially avoidable, it emphasizes the need for a constant monitoring and review of head injury management in the A\&E setting.

However, the number of patients who were managed inappropriately may be higher than this. Firstly, probable under-recording, miscoding and lost medical records may have given an inaccurate picture of the true incidence of head injuries in the Brighton Health District. Secondly, the accuracy of the results is dependent upon the quality and content of the medical records.

The content and legibility of the medical records reviewed in this study was poor. Only loss of consciousness and the length of time unconscious were well documented (Table 3 ). The absence of relevant details and the presence of poor quality clinical information made it difficult to decide objectively whether a patient had been managed appropriately.

Peer review helped decide whether patients had been managed correctly, but inevitably this made the process more subjective, potentiating the introduction of observer variation. It might have been more accurate to have had a third category where no judgement could be made because of insufficient information, but this would have included almost the entire sample.

Therefore, the result of $84 \%$ of patients having been managed correctly may well be over-optimistic, implying that any further study would necessitate much improved documentation for head-injured patients. In order to improve the quality of documentation (both in legibility and content) and to simplify and standardize the assessment of head-injured patients, a recommendation for developing a head injury pro forma to address these issues in the $A \& E$ department was suggested.

As well as documentation, the reliability of the results was also dependent upon the accuracy of the criteria themselves. They must be unambiguous to minimize inter-observer error and be of proven scientific value. The time taken to clearly identify and explicitly define the criteria is a prerequisite of a successful criterion based audit.

In this study, three fractures would have been missed if the criteria for ordering an SXR had been adhered to strictly. Two of these were in young babies, which raises questions about the validity of such criteria in this age group. Recent evidence suggests that children (under 14 years) are at a lesser risk of intracranial haematoma than adults ${ }^{28}$ and that fewer children have evidence of brain damage as the result of a head injury. ${ }^{34}$ Although the main indicators of risk, a skull fracture and conscious level, are the same as for adults, ${ }^{28}$ the clinical criteria used in this study failed to diagnose these fractures.

Some criteria may need revision in order that they can be applied to the younger age group. For example, criteria about abnormal behaviour or play and altered eating and drinking habits might be more applicable to young children and babies than criteria about post-traumatic amnesia and visual disturbance. Evidence from one group concluded that there is an urgent need for regions to revise their guidelines to include recommendations for optimal practice for assessing children with severe head injuries. ${ }^{35}$

The potential to miss skull fractures highlights the problem with unduly prescriptive standard setting and possible inappropriate restrictions. A recent case study described a patient who did not satisfy any of the usual criteria for SXR, yet assessment of the mechanism of injury revealed that the patient's head had been subjected to an impact of significant velocity against a hard surface and the risk of vault fracture therefore was judged to be high. ${ }^{36}$ An SXR revealed a $6-\mathrm{cm}$ linear fracture of the right occipitoparietal region. Following neurosurgical consultation, a CT scan was performed and showed a large extradural haematoma which was successfully evacuated with no residual neurological sequelae.

Guidelines are not static and must be updated continually to take account of changes in medical knowledge and practice. ${ }^{37}$ At the same time, guidelines should reflect the large areas of uncertainty in management honestly and not attempt to stifle healthy variation in practice. ${ }^{38}$ Mechanism of injury suggesting considerable force should be an integral part of both national and local guidelines for managing patients with head injury. ${ }^{36,39}$

The primary reason for performing an SXR is to 
S.A. Wallace et al. exclude a skull fracture, as the presence of a fracture increases the risk of a serious outcome, $, 9,32,33$ particularly that of intracranial haematoma. Early diagnosis of an intracranial haematoma followed by prompt surgical intervention has reduced the morbidity and mortality resulting from this lesion appreciably. 8,25

However, over recent years there has been much discussion about the indication for this test, with radiologists ${ }^{17,32,40}$ favouring a more selective policy compared with neurosurgeons. ${ }^{41,42}$ A\&E doctors have recently examined reasons why criteria were being ignored and have suggested slight alterations to the 1986 Working Party guidelines. ${ }^{43}$ The objective of any diagnostic procedure is to subject the patient to the test only when risk (excess radiation in this case), cost and inconvenience are outweighed by the potential value of the result. A combination of medicolegal issuses, patients' expectations and a previous lack of objective screening guidelines has exerted great pressure on the clinician to subject large numbers of patients to radiography, regardless of clinical judgement.

The purpose of admitting a patient with a head injury is either to treat an obvious lesion or observe a patient who may develop complications. ${ }^{8}$ Although all admissions in this study were judged to be appropriate, four cases were identified that should have been admitted. The adverse outcome (death) of one of these patients highlights the importance of adherence to recommended criteria.

Despite some evidence satisfying the criteria in the medical records of 27 patients who were managed inappropriately, the A\&E doctors' reason for his/her management was unknown. Although there was an induction course covering head injury management at the start of their appointment, there could have been either an unfamiliarity with the criteria or a general lack of knowledge about managing patients with a head injury.

In conclusion, this study has highlighted the advantages and disadvantages of using guidelines and criteria. It has demonstrated that the poor quality of medical record content and poor legibility made the process less objective than was originally planned, thus potentially lowering the true number of patients who were managed correctly. It has also shown that some of the criteria were not entirely appropriate, particularly for babies.

Several recommendations have been made to improve the management of head injuries. Firstly, a head injury pro forma should be developed and piloted in several A\&E departments. ${ }^{44}$ Secondly, the quality of the criteria should be studied, particularly for mechanism of injury, and the criteria for babies and young children require further discussion and consideration. Thirdly, as emphasized in a recent audit, ${ }^{45}$ local A\&E departments should publicize the criteria more widely by including them in the junior doctors handbook, displaying them as a poster in the A\&E department and making them an integral part of the A\&E doctor's induction course.

\section{ACKNOWLEDGEMENTS}

Acknowledgement is due to Mr A. Clark, Consultant Surgeon of the Royal Sussex County Hospital in Brighton for peer reviewing cases in this study. The authors are also grateful to Ms Gitta Horan for word processing assistance during the preparation of this manuscript.

\section{REFERENCES}

1. South East Thames Regional Health Authority (1989) A Regional Policy. Care of patients with acute head injury in district general hospitals,

2. Jennett B. \& Carlin C. (1978) Preventable mortality and morbidity after head injury. Injury 10, 31-39.

3. Royal College of Surgeons of England (1986) Commission on the provision of surgical services. Report of the Working Party on Head Injuries, London.

4. Oxford Regional Health Authority (1990) Regional policies on the management of patients with a head injury. A discussion document. Physical Disability Working Group, Oxford.

5. James J.J. \& Jefferies R.V. (1981) Relative risks of alternative admission policies for patients with head injuries. Lancet ii, 850.

6. Mendelow A.D., Cambell D.A., Jeffrey R.R., Miller J.D., Hessett C., Bryden J. \& Jennett B. (1982) Admission after a mild head injury: benefits and costs. British Medical Journal 285, 1530-1532.

7. Bryden J.S. \& Jennett B. (1983) Neurosurgical resources and transfer policies for head injuries. British Medical Journal 286, 1791-1793.

8. A Group of Neurosurgeons (1984) Guidelines for initial management of head injury in adults. British Medical Journal 288, 983-985.

9. Bell R.S. \& Loop J.W. (1971) The utility and futility of radiographic skull examination for trauma. New England Journal of Medicine 284, 236-239.

10. Evans K.T. (1977) The radiologists dilemma. British Journal of Radiology 50, 299-301.

11. Eyes B. \& Evans A.F. (1978) Post traumatic skull radiographs: time for reappraisal. Lancet ii, 85-86.

12. Boulis Z.F., Dick R. \& Barnes N.R. (1978) Head injury in children - aetiology, symptoms, physical findings and X-ray wastage. British Journal of Radiology 51 , $851-854$. 
Head injuries in A\&E
13. Philips L.A. (1979) Comparative evaluation of the effect of a high-yield criteria list upon skull radiography. Journal of the American College of Emergency Physicians 8, 106-109.

14. Masters S.J. (1980) Evaluation of head trauma: efficacy of skull films. American Journal of Roentgenology 135, 329-327.

15. Royal College of Radiologists (1980) A National Study by the Royal College of Radiologists. A study of the utilisation of skull radiography in nine accident and emergency units in the United Kingdom. Lancet ii, 1234-1236.

16. Gorman D.F. (1987) The utility of post-traumatic skull X-rays. Archives of Emergency Medicine 4, 141-150.

17. Fowkes F.G.R., Williams L.D., Cooke B.R.B., Evans R.C., Gehlbach S.H. \& Roberts C.J. (1984) Implementation of guidelines for the use of skull radiographs in patients with head injuries. Lancet ii, 795-797.

18. Royal College of Radiologists Working Party (1992) Influence of the Royal College of Radilogists' guidelines on hospital practice: a multicentre study. British Medical Journal 304, 740-743.

19. Guys and Lewisham Trust Procedure Prices (personal communication).

20. Weston P.A.M. (1981) Admission policy for patients following head injury. British Journal of Surgery 68, 663-664.

21. Edna T.H. \& Cappelen J. (1984) Hospital admission for head injury. A prospective study in Trondelag, Norway. 1979-80. Scandinavian Journal of Social Medicine 12, 7-14.

22. Sandeman D.R. \& Cummins B.C. (1986) The provenance of extradural haematomas. British Medical Journal 292, 522-523.

23. Bowers S.A. \& Marshall L.F. (1980) Outcome in 200 consecutive cases of severe head injury treated in San Diego County: a prospective analysis. Neurosurgery 6, 237-242.

24. Cordobes F., Lobato R.D., Rivas J.J. et al. (1981) Observations on 82 patients with extradural haematoma. Comparisons of results before and after the advent of computed tomography. Journal of Neurosurgery 54, 179-186.

25. Teasdale G., Galbraith S., Murray L., Ward P., Gentleman D. \& McKean M. (1982) Management of traumatic intracranial haematoma. British Medical Journal 285, 1695-1697.

26. Bricolo A.P. \& Parker L.M. (1984) Extradural haematoma. Towards zero mortality. Neurosurgery 14, 8-12.

27. Miller J.D., Tocher J.C. \& Jones P.A. (1988) Extradural haematoma - earlier detection, better results. Brain Injury 2, 83-86.

28. Teasdale G.M., Murray G., Anderson E., Mendelow A.D., MacMillan R., Jennett B. \& Brookes M. (1990) Risk of acute intracranial haematoma in children and adults: implication for managing head injuries. British
Medical Journal 300, 363-367.

29. Department of Health and Social Security (1983) The management of acute head injury. Harrogate Seminar Report No. 8. 1983, London.

30. Shaw C.D. (1989) Audit in internal medicine. British Journal of Hospital Medicine 42, 19.

31. Shaw C.D. (1990) Criterion based audit. British Medical Journal 300, 649-651.

32. Mendelow A.D., Teasdale G., Jennett B., Bryden J., Hassett C. \& Murray G. (1983) Risks of intracranial haematoma in head-injured adults. British Medical Journal 287, 1173-1176.

33. Royal College of Radiologists (1981) National study by the Royal College of Radiologists. Costs and benefits of skull radiography for head injury. Lancet ii, 791-795.

34. Brookes M., MacMillan R., Cully S., Anderson E., Murray S., Mendelow A.D. \& Jennett B. (1990) Head injuries in accident and emergency departments. How different are children from adults? Journal of Epidemiology and Community Health 4, 147-151.

35. Sharples P.M., Storey A., Aynsley-Green A. \& Eyre J.A. (1990) Avoidable factors contributing to death of children with head injury. British Medical Journal 300, 87-91.

36. Nee P.A., Phillips B.M. \& Bannister C.M. Extradural haematoma in a child after an apparently mild head injury. British Medical Journal 306, 1665-1666.

37. Haines A. \& Feder G. (1992) Guidance on guidelines: writing them is easier than making them work. British Medical Journal 305, 785-786.

38. Editorial (1992) Guidelines for doctors in the new world. Lancet 339, 1197-1198.

39. Wallace S.A. \& Gullan R.W. (1993) Mild head injury. Guidelines should be flexible. British Medical Journal 307, 447-448.

40. Evans K.T., Roberts C.J. \& Ennis E.W. (1983) Head injuries in adults. British Medical Journal 287 , 1882-1883.

41. Jennett B. (1980) Skull X-rays after recent head injury. Clinical Radiology 31, 463-469.

42. Galbraith S., MacMillan R. \& Jennett B. (1981) X-rays for skull fractures. Lancet i, 272.

43. MacLaren R.E., Ghoorahoo H.I. \& Kirby N.G. (1993) Skull $X$-ray after head injury: the recommendations of the Royal College of Surgeons Working Party Report in practice. Archives of Emergency Medicine 10, 138-144.

44. Wallace S.A., Gullan R.W., Byrne P.O., Bennett J. \& Perez-Avila C. (1993) Use of a pro forma for head injuries in the accident and emergency department the way forward. Journal of Accident and Emergency Medicine 11, 33-42.

45. Madhok R., Thomson R.G., Mordue A., Mendelow A.D. \& Barker J. (1993) An audit of distribution and use of guidelines for management of head injury. Quality in Health Care 2, 27-30. 